\title{
The Dissimilar Self-Alignment Characteristics of Smaller Passive Components in the Length and Width Directions
}

\author{
Jingxi He', Yuqiao Cen', Yuanyuan Li', Seungbae Park², Daehan Won' \\ ${ }^{1}$ Department of Systems Science and Industrial Engineering \\ ${ }^{2}$ Department of Mechanical Engineering \\ State University of New York at Binghamton \\ Binghamton, New York, USA
}

\begin{abstract}
Motivation: As passive components' size gets smaller, quality rejects due to overhangs after the reflow appear more frequently. This situation is partly because the pass-fail criterion is set based on the offset concerning the component and pad dimensions. Therefore, understanding the self-alignment characteristics of electronic components becomes very critical for surface-mount assembly yield. This research investigates the dissimilarity of selfalignment in the length and width directions.

Approach: To avoid the argument of sample to sample variations, data are collected from 81 printed circuit boards (PCB) and 182,250 assembled components. Within a PCB, 25 different solder paste printing offset locations and 81 component placement offset settings are implemented. Component-placement positions before and after the reflow are monitored. The results are compared to identify different component sizes' self-alignment characteristics in the length and width directions.

Key findings: The misalignment of smaller passive components, e.g., R0402M $(0.40 \mathrm{~mm} \times 0.20 \mathrm{~mm})$, is worse than the larger component under the identical solder paste printing and component placement conditions. Furthermore, the self-alignment characteristic in the length direction of these passive components, e.g., R0402M, to R1005M (1.00 mm $\times 0.50 \mathrm{~mm})$ is superior to that of width direction. The observations are not consistent with the results found in earlier research that reported on the capacitors and resistors in variant sizes, e.g., $0402 \mathrm{M}(0.40 \mathrm{~mm} \times 0.20 \mathrm{~mm})$, to $3216 \mathrm{M}(3.20 \mathrm{~mm} \times 1.60 \mathrm{~mm})$.
\end{abstract}

Keywords SMT assembly, smaller passive components, selfalignment in length, self-alignment in width

\section{INTRODUCTION}

Surface mount technology (SMT) provides assembly solutions of components on a printed circuit board (PCB) with automated machines to meet the high-volume production requirement in electronic products.

In general, the SMT process contains three operations: the stencil printing process (SPP), pick-and-place (chip mounting) process, and reflow soldering [1-3]. First, solder paste is printed onto the surface of a PCB by a stencil printer. Then, surface mount components (SMCs) are placed on the PCB by pick-and-place machines. Lastly, the PCB is sent to a reflow oven to form a solder interconnection between components and pads on the PCB.

During the reflow process, the surface tension between the molten solder and mating $\mathrm{Cu}$ pads, causes the SMCs to move to the most stable position and automatically ensure the desired alignment [4], an effect is known as self-alignment. Self-alignment is one of the critical characteristics of a successful reflow process [5-7]. A comprehensive understanding of the characteristics of components self-alignment is vital to enhance SMCs' assembly quality. In terms of the passive components' directional movements, self-alignment characteristics have been well studied through simulation models and small-scale lab experiments [10-12]. However, for smaller SMCs, greater assembly related yield losses are observed [11]. This is because the ratio of the offset to the component size is one of the critical criteria to the assembly quality according to IPC Standards [13], which defines the side overhang should be less than or equal to $25 \%$ of the smaller value between width of component termination area and width of land, and no end overhang is permitted for acceptable Class 3 products. In this study, according to the IPC acceptable standards, the side overhang limits are $25 \%$ of the components' width dimensions, and the end overhang tolerances are $25 \%$ of the components' length dimensions. In practical, the pad size usually decreases with the shrinking component size. It means the offset value that is acceptable for large component can cause a failure in the smaller one. Thus, a thorough understanding of smaller components' self-alignment characteristics is essential to enhancing the quality and yield of the electronics assemblies.

To study this systematically, an experiment with 81 design of experiment (DOE) PCBs and 182,250 components is implemented. Chip resistors, R0402M, R0603M, and R1005M are selected in this experiment because they are widely used in 
the smaller and lighter electronic devices [12]. The dimensions and weight details of the components used in our research are stated in Figure 1.

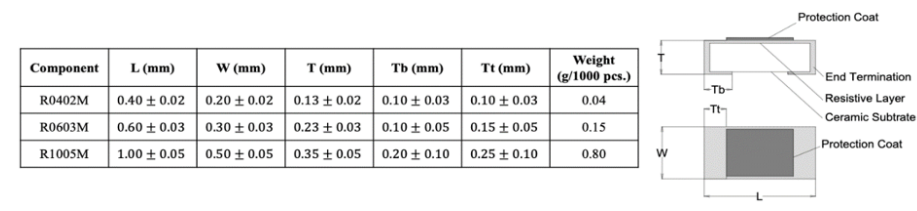

Figure 1: The dimensions and weight details of the three types of components.

\section{PRIOR RESEARCH}

At the beginning of the SMT, studies mainly focused on the self-alignment effects of large passive components [10]. The first simple two-dimensional force model was proposed in 1986 to predict the component movement and prevent the tombstoning defect [9]. The study used a straight-lined solder fillet to predict component movement during the reflow process. Nevertheless, components' real behaviors could not be modeled correctly because the overly simplified model did not consider the liquid solder's hydrostatic pressures.

A dynamic two-dimensional model was then developed to establish the relationship between the component-placement offset and solder joint reliability [8]. SMT-type 3216M chip capacitor $(3.20 \mathrm{~mm} \times 1.60 \mathrm{~mm})$ was the only component type used in this study. The component used in this study cannot explain the self-alignment behaviors of tiny passive chip components that are now widely used.

Later, a 3D force model was proposed [4]. In that study, compared with the components we considered in our study, larger components - a chip resistor $1608 \mathrm{M}(1.60 \mathrm{~mm} \times 0.80 \mathrm{~mm})$ and chip capacitor $1608 \mathrm{M}(1.60 \mathrm{~mm} \times 0.80 \mathrm{~mm})$ - were used to study the self-alignment behavior. The experimental results showed that chip resistors had moved less in the component length direction than in the width direction.

More recently, a study compared the effect of positional offset on the restoring force and distance traveled in the length and width directions [10]. The results showed that the degree of restoring force in the component's width direction is greater than that in the length direction for resistors $1608 \mathrm{M}$.

A relatively new study investigated the relationship between positional offset and distance traveled in the length and width directions during reflow [13]. Chip resistors 0603M and different types of solder have been used in the study. The results demonstrated that chip components have a better self-alignment in the component width direction than in the length direction for all kinds of solder paste.

In recent research, Surface Evolver has been used to study the solder joint surface [14]. It is a simulation program to model the solder joint equilibrium by including surface tension, gravitational effects, and internal and external pressures [15]. In [16], Surface Evolver was used to build a 3D model to predict components' selfalignment behaviors. Three types of components, chip capacitors
C1005M $(1.00 \mathrm{~mm} \times 0.50 \mathrm{~mm})$, C0603M $(0.60 \mathrm{~mm} \times 0.30 \mathrm{~mm})$, and C0402M $(0.40 \mathrm{~mm} \times 0.20 \mathrm{~mm})$, were included. The research illustrated the relationship between offset and restoring force for the length and width directions. The simulation confirmed that the passive components self-aligned better in the width direction than the length direction.

To validate the previous research, an experiment using chip resistors R0402M, R0603M and R1005M is designed. The experimental details and the comparative discussions about the results will be elaborated in the following parts.

\section{ON-SITE EXPERIMENTAL DESIGN}

To study the self-alignment behaviors of miniature passive components under different solder paste positions and component placement positions, we designed a stencil with 25 intentional solder paste offset settings. Eighty-one different component placements setting were implemented in the study. Resistors, R0402M, R0603M, and R1005M are used to compare the selfalignment effects on different sizing passive components. Each resistor type has batches of 750 components placed on a board. Half of the components are placed so their length runs parallel to the $\mathrm{x}$-axis of a board. They are said to run horizontally, or at 0 degrees. The other half are placed so their width runs parallel to the $\mathrm{x}$-axis. They are said to run vertically, or at 90 degrees. Each of the 81 boards has 750 components of each resistor type, meaning the whole experiment evaluates 182,250 components.

The experiment is conducted in an on-site production line in the laboratory, where there is an MPM Momentum printer, a Koh Young Aspire3 solder paste inspection (SPI) machine, a Universal Instruments Fuzion pick-and-place (P\&P) machine, a Koh Young Zenith pre-reflow automatic optical inspection (AOI) machine, a Heller convection reflow oven, and a Koh Young Zenith post-reflow AOI machine. The layout of the production line is presented in Figure 2. According to the manufacturers' reports, SPI and AOI machines' inspection accuracy are $\pm 15 \mu \mathrm{m}$, and the P\&P machine's accuracy is $\pm 34 \mu \mathrm{m}$.

Because horizontal and vertical placements are implemented in the study, $\mathrm{L}$ and $\mathrm{W}$ are used instead of $\mathrm{x}$ and $\mathrm{y}$ as the coordinates in the dataset to avoid potential confusion. L represents the measurements in the components' length direction, W represents the measurements in the components' width direction. Further experimental details will be introduced in the following subsections.

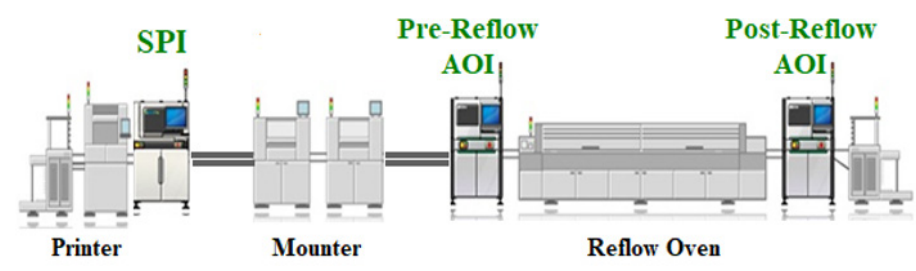

Figure 2: The layout of the experimental production line [17] 


\section{PCB Design}

The single-sided FR-4 (woven glass and epoxy) PCB size is $160 \mathrm{~mm} \times 130 \mathrm{~mm}$, and the arrangement of the components on the board is illustrated in Figure 3. In the figure, $0^{\circ}$ represents horizontal placement and $90^{\circ}$ represents vertical placement.

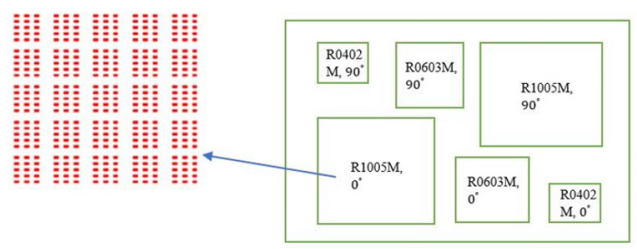

Figure 3: The layout of the components on the РСВ

The distance from the board edge to the pad is $29 \mathrm{~mm}$. According to the industrial experience, the designed land pattern dimensions are shown in Table I and Figure 4.

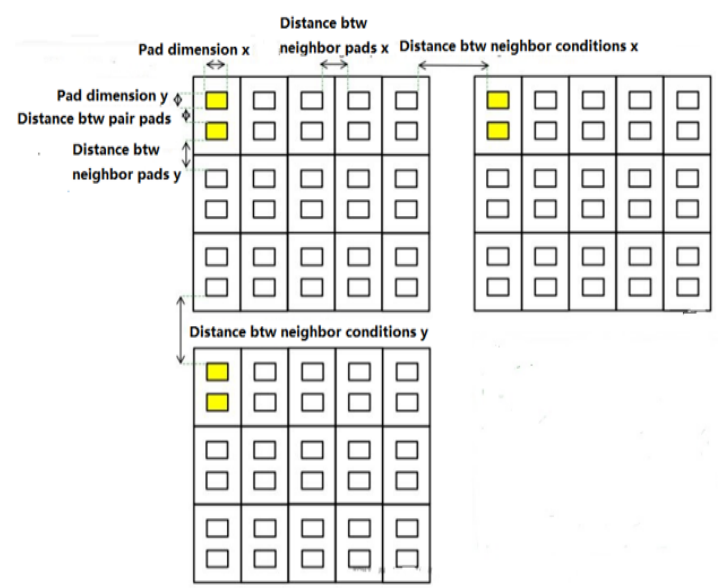

Figure 4: The definition of the land pattern parameters

Table I: The land pattern dimensions for each component type

\begin{tabular}{|c|c|c|c|c|c|c|}
\hline \multirow{2}{*}{} & \multicolumn{2}{|c|}{$\mathrm{R} 0402 \mathrm{M}$} & \multicolumn{2}{c|}{$\mathrm{R} 0603 \mathrm{M}$} & \multicolumn{2}{c|}{$\mathrm{R} 1005 \mathrm{M}$} \\
\cline { 2 - 7 } & $\mathrm{x}(\mathrm{mm})$ & $\mathrm{y}(\mathrm{mm})$ & $\mathrm{x}(\mathrm{mm})$ & $\mathrm{y}(\mathrm{mm})$ & $\mathrm{x}(\mathrm{mm})$ & $\mathrm{y}(\mathrm{mm})$ \\
\hline $\begin{array}{c}\text { Pad } \\
\text { dimension }\end{array}$ & 0.22 & 0.22 & 0.33 & 0.33 & 0.56 & 0.56 \\
\hline $\begin{array}{c}\text { Distance } \\
\text { between } \\
\text { pair pads }\end{array}$ & $\mathrm{N} / \mathrm{A}$ & 0.16 & $\mathrm{~N} / \mathrm{A}$ & 0.26 & $\mathrm{~N} / \mathrm{A}$ & 0.45 \\
\hline $\begin{array}{c}\text { Distance } \\
\text { between } \\
\text { neighbor } \\
\text { pads }\end{array}$ & 0.7 & 0.7 & 1.02 & 1.02 & 1.68 & 1.68 \\
\hline $\begin{array}{c}\text { Distance } \\
\text { between } \\
\text { neighbor } \\
\text { conditions }\end{array}$ & 0.8 & 1.22 & 1.22 & 1.88 & 2.11 & 3.13 \\
\hline
\end{tabular}

Notes: N/A indicates the measurements' unavailability because it is based on the vertical placement setting.

\section{Solder Printing Settings}

A stencil is designed to guarantee the solder paste offsets on each PCB are identical. The thickness of the nano-coating stainless steel stencil is $76.2 \mu \mathrm{m}$. The aperture shape format and size information are presented in Figure 5 and Table II, where Corner Ratio $=\mathrm{r} /($ Length $/ 2)$. In the solder printing process, the printing speed and separation speed are set as $33 \mathrm{~mm} / \mathrm{s}$ and 80 $\mathrm{mm} / \mathrm{s}$, respectively. The printing pressure is $8 \mathrm{~kg}$.

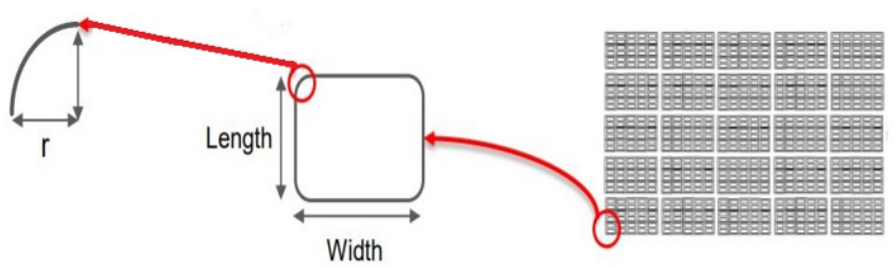

Figure 5: The aperture shape format of the stencil

Table II: The stencil aperture size of each component type

\begin{tabular}{|c|c|c|c|c|c|}
\hline Component & $\begin{array}{c}\text { Length } \\
(\mathrm{mm})\end{array}$ & $\begin{array}{c}\text { Width } \\
(\mathrm{mm})\end{array}$ & $r(\mathrm{~mm})$ & $\begin{array}{c}\text { Corner } \\
\text { Ratio }\end{array}$ & $\begin{array}{c}\text { Area } \\
\text { Ratio }\end{array}$ \\
\hline R0402M & 0.2051 & 0.2256 & 0.0513 & $50 \%$ & 0.7 \\
\hline R0603M & 0.3074 & 0.3483 & 0.0768 & $50 \%$ & 1.1 \\
\hline R1005M & 0.5124 & 0.5739 & 0.1281 & $50 \%$ & 1.8 \\
\hline
\end{tabular}

Because there are two pads employed for a single passive component, the pad center in this paper refers to the twodimensional geometrical center point of the two pads. Regarding the solder paste related parameters, the paste offsets are the distance measurements from the center point of the two solder pastes for each component to the corresponding pad center, as shown in Figure 6. The paste volume is the mean value of the two solder pastes volumes of each component.

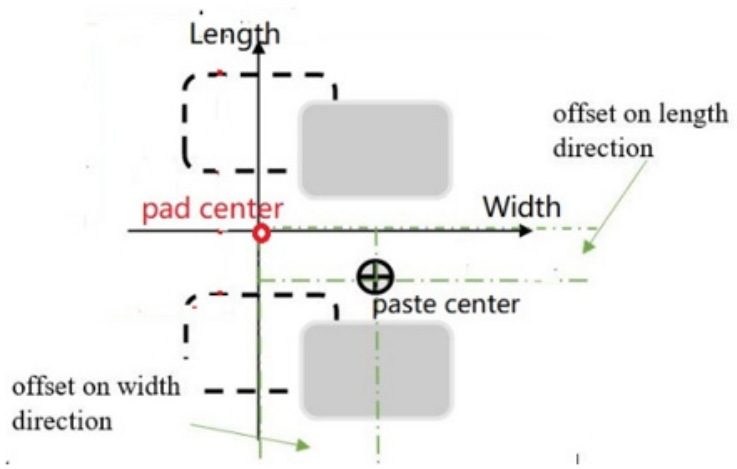

Figure 6: The definition of the solder paste offset parameters

For each component type, 25 solder paste offset settings are designed in the stencil. The offset values range from $-20 \%$ to $+20 \%$ of the component size in length and width direction with a $10 \%$ step size. The details are illustrated in Table III. For example, the setting $(10 \%, 10 \%)$ of R0402M means the solder design offset 
is $10 \% \times 0.4 \mathrm{~mm}$ for length and $10 \% \times 0.2 \mathrm{~mm}$ for width to the positive direction. The positive direction is defined as shown in Figure 7 . The $\pm 20 \%$ was chosen as the lower and upper bound of offset settings because the design offset should meet the industry criteria, which defines the side overhang should be less than or equal to $25 \%$ width of component termination area, and no end overhang is permitted for Class 3 products in IPC standard [18].

To strengthen the experiments' reliability, we replicate the experiments 15 times for each setting, including solder paste offset and component placement offset.

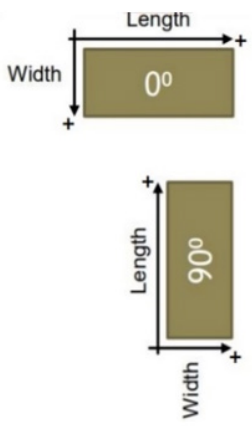

Figure 7: The positive direction of the offset for horizontal and vertical placement along the length and width directions. Notes: $0^{\circ}$ represents horizontal placement, $90^{\circ}$ represents vertical placement.

\section{Pick-and-place Placement Settings}

The placement offset settings range from $-20 \%$ to $+20 \%$ of component size on length and width direction with the step size of $5 \%$. For example, the setting $(5 \%,-5 \%)$ of R0402M means the component placement offset is $5 \% \times 0.4 \mathrm{~mm}$ in length and $-5 \% \times 0.2 \mathrm{~mm}$ in the width direction. The definitions of negative and positive offsets are the same as that of solder paste offsets. The 81 placement settings are presented in Table IV. Because one unique placement setting is engaged for each board, 81 boards are produced for this experiment to correspond to the 81 settings.

The definitions of positive and negative placement offsets are equivalent to the solder paste offsets.

\section{Solder Reflow Settings}

A 7-zone Heller $1700 \mathrm{~W}$ convection reflow oven and Indium8.9HF Pb-Free SAC305 solder paste are used in the experiments. According to the solder paste manufacturer's recommendation, each zone's reflow temperatures are set as $140^{\circ} \mathrm{C}$ in the preheating zone, $170^{\circ} \mathrm{C}$ in the pre-reflow zone, and $270^{\circ} \mathrm{C}$ in the reflow zone with Nitrogen as the reflow atmosphere. The conveyor speed is 30 inches/min, i.e., 1.27 $\mathrm{cm} / \mathrm{s}$, and the PCBs are forwarded to the oven in the length wise direction. ECD Super MOLE Gold2 thermal profiler is used to monitor the reflow temperatures in the solder reflow process.

Table III: The given settings for the solder paste printing offset

\begin{tabular}{|c|c|c|c|c|c|c|}
\hline \multirow{2}{*}{\multicolumn{2}{|c|}{}} & \multicolumn{3}{|c|}{ The length offset from pad center (percentage of the component length) } \\
\cline { 3 - 7 } & $-20 \%$ & $-10 \%$ & $0 \%$ & $10 \%$ & $20 \%$ \\
\hline \multirow{2}{*}{$\begin{array}{c}\text { The width } \\
\text { offset from } \\
\text { pad center }\end{array}$} & $-20 \%$ & $(-20 \%,-20 \%)$ & $(-10 \%,-20 \%)$ & $(0 \%,-20 \%)$ & $(10 \%,-20 \%)$ & $(20 \%,-20 \%)$ \\
\cline { 2 - 7 } $\begin{array}{c}\text { (percentage of } \\
\text { the component } \\
\text { width) }\end{array}$ & $-10 \%$ & $(-20 \%,-10 \%)$ & $(-10 \%,-10 \%)$ & $(0 \%,-10 \%)$ & $(10 \%,-10 \%)$ & $(20 \%,-10 \%)$ \\
\cline { 2 - 7 } & $10 \%$ & $(-20 \%, 0 \%)$ & $(-10 \%, 0 \%)$ & $(0 \%, 0 \%)$ & $(10 \%, 0 \%)$ & $(20 \%, 0 \%)$ \\
\hline
\end{tabular}

Table IV: The components' placement offset settings (\%)

\begin{tabular}{|c|c|c|c|c|c|c|c|c|c|c|}
\hline & \multicolumn{9}{|c|}{ The length offset from pad center (percentage of the component length) } \\
\hline & & -20 & -15 & -10 & -5 & 0 & 5 & 10 & 15 & 20 \\
\hline \multirow{9}{*}{$\begin{array}{l}\text { The width } \\
\text { offset from } \\
\text { pad center } \\
\text { (percentage } \\
\text { of the } \\
\text { component } \\
\text { width) }\end{array}$} & -20 & $(-20,-20)$ & $(-15,-20)$ & $(-10,-20)$ & $(-5,-20)$ & $(0,-20)$ & $(5,-20)$ & $(10,-20)$ & $(15,-20)$ & $(20,-20)$ \\
\hline & -15 & $(-20,-15)$ & $(-15,-15)$ & $(-10,-15)$ & $(-5,-15)$ & $(0,-15)$ & $(5,-15)$ & $(-20,-15)$ & $(15,-15)$ & $(-20,-15)$ \\
\hline & -10 & $(-20,-10)$ & $(-15,-10)$ & $(-10,-10)$ & $(-5,-10)$ & $(0,-10)$ & $(5,-10)$ & $(10,-10)$ & $(15,-10)$ & $(20,-10)$ \\
\hline & -5 & $(-20,-5)$ & $(-15,-5)$ & $(-10,-5)$ & $(-5,-5)$ & $(0,-5)$ & $(5,-5)$ & $(10,-5)$ & $(15,-5)$ & $(20,-5)$ \\
\hline & 0 & $(-20,0)$ & $(-15,0)$ & $(-10,0)$ & $(-5,0)$ & $(0,0)$ & $(5,0)$ & $(10,0)$ & $(15,0)$ & $(20,0)$ \\
\hline & 5 & $(-20,5)$ & $(-15,5)$ & $(-10,5)$ & $(-5,5)$ & $(0,5)$ & $(5,5)$ & $(10,5)$ & $(15,5)$ & $(20,5)$ \\
\hline & 10 & $(-20,10)$ & $(-15,10)$ & $(-10,10)$ & $(-5,10)$ & $(0,10)$ & $(5,10)$ & $(10,10)$ & $(15,10)$ & $(20,10)$ \\
\hline & 15 & $(-20,15)$ & $(-15,15)$ & $(-10,15)$ & $(-5,15)$ & $(0,15)$ & $(5,15)$ & $(10,15)$ & $(15,15)$ & $(20,15)$ \\
\hline & 20 & $(-20,20)$ & $(-15,20)$ & $(-10,20)$ & $(-5,20)$ & $(0,20)$ & $(5,20)$ & $(10,20)$ & $(15,20)$ & $(20,20)$ \\
\hline
\end{tabular}


The reflow recipe and the temperature measurements from sensors are demonstrated in Table $\mathrm{V}$ and Figure 8 individually. In Table V, only the six zones' temperatures are displayed because the last zone (i.e., Zone 7) is the cooling zone. In Figure 8, the curves reflect the real temperatures gathered from five locations on the PCB during reflow.

Table V: The temperature setting of each zone in the reflow oven

\begin{tabular}{|c|c|c|c|c|c|c|}
\hline & $\begin{array}{c}\text { Zone } \\
1\end{array}$ & $\begin{array}{c}\text { Zone } \\
2\end{array}$ & $\begin{array}{c}\text { Zone } \\
3\end{array}$ & $\begin{array}{c}\text { Zone } \\
4\end{array}$ & $\begin{array}{c}\text { Zone } \\
5\end{array}$ & $\begin{array}{c}\text { Zone } \\
6\end{array}$ \\
\hline $\begin{array}{c}\text { Temperature } \\
\text { settings }\end{array}$ & $100^{\circ} \mathrm{C}$ & $140^{\circ} \mathrm{C}$ & $155^{\circ} \mathrm{C}$ & $170^{\circ} \mathrm{C}$ & $190^{\circ} \mathrm{C}$ & $270^{\circ} \mathrm{C}$ \\
\hline
\end{tabular}

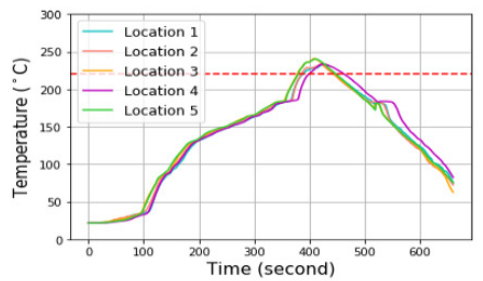

(a)

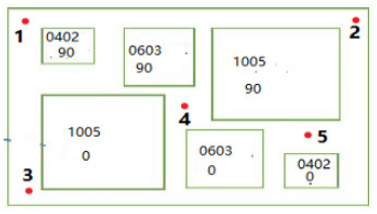

(b)
Figure 8: The monitored real-time temperatures of the five locations on the PCB. Notes: (a) The thermal profiler data of the temperatures for the five locations; (b) the positions of the five locations on the PCB.

\section{DISCUSSIONS OF THE EXPERIMENTAL RESULTS}

Experimental results of horizontal versus vertical placement

The distances from each component center to the pad center after the reflow are measured to assess any different horizontal and vertical placement patterns. Because of the large sample size for each placement under various placement settings, visual tests combined with numeric comparison instead of statistical significance tests are applied to compare the two populations' post-reflow distances for each component type. The details are demonstrated in Figure 9 (a)-(c) and Table VI, where 0 represents horizontal placement (i.e., $0^{\circ}$ of the placement rotation), and 90 represents vertical placement (i.e., $90^{\circ}$ of the placement rotation), $\mathrm{M}$ and std stand for mean and standard deviation separately.

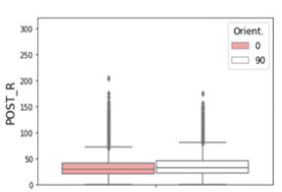

(a)

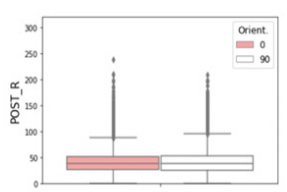

(b)

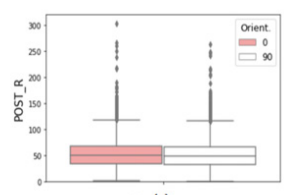

Figure 9: The component post-reflow offset distances comparison between horizontal and vertical placement for each component type Notes: (a) Comparison of R0402M; (b) Comparison of R0603M; (c) Comparison of R1005M.
Table VI: The results of the component post-reflow offsets for each component type

\begin{tabular}{|c|c|c|c|c|}
\hline Component & $\begin{array}{c}\text { Dist. M } \\
0(\mu \mathrm{m})\end{array}$ & $\begin{array}{c}\text { Dist. std } \\
0(\mu \mathrm{m})\end{array}$ & $\begin{array}{c}\text { Dist. M } \\
90(\mu \mathrm{m})\end{array}$ & $\begin{array}{c}\text { Dist. std } \\
90(\mu \mathrm{m})\end{array}$ \\
\hline R0402M & 31.82 & 17.16 & 34.56 & 17.91 \\
\hline R0603M & 40.19 & 21.63 & 41.08 & 22.84 \\
\hline R1005M & 51.91 & 24.43 & 50.02 & 23.97 \\
\hline
\end{tabular}

The results of Figure 9 and Table VI indicate that there is no significant difference between horizontal and vertical placement regarding the post-reflow distances.

Experimental results of the solder paste volume for different sized components

The solder paste volumes are examined to identify the possible effects of different paste volumes on moving distances during reflow. The results are shown in Figure 10 (a)-(c) and prove the solder paste volumes are well controlled in general in this experiment. More specifically, the average, standard deviation, minimum, and maximum of the percentages of solder paste volume for R0402M, R0603M, and R1005M are $(79.4$ $3 \%, 7.69 \%, 56.36 \%, 212.28 \%), \quad(77.82 \%, 9.23 \%, 49.88 \%, 171.08 \%)$, $(83.18 \%, 9.31 \%, 51.64 \%, 158.37 \%)$, respectively. The $100 \%$ solder paste volumes for R0402M, R0603M, and R1005M are 0.0035 $\mathrm{mm}^{3}, 0.0078 \mathrm{~mm}^{3}$, and $0.0210 \mathrm{~mm}^{3}$ separately. Particularly, there are no significant differences in terms of the solder paste volume percentages among the three types of components.

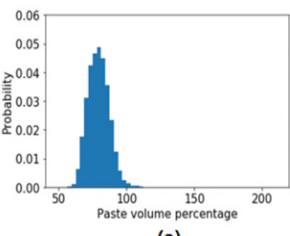

(a)

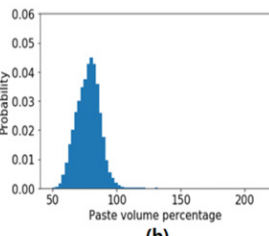

(b)

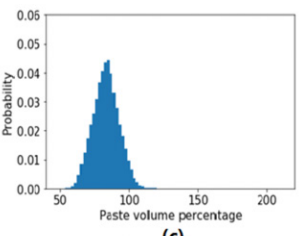

(c)
Figure 10: The solder paste volume percentage distribution of each component type. Notes: (a) The solder paste volume percentage distribution of R0402M; (b) the solder paste volume percentage distribution of R0603M; (c) the solder paste volume percentage distribution of R1005M.

Experimental results comparison for different component sizes

To compare the self-alignment effects on different component sizes, we define a new performance metric, the $\alpha$-qualification rate $\left(\mathrm{QR}_{\alpha}\right)$, which evaluates the post-reflow outcome by calculating the ratio of the components whose offsets are within $\alpha \%$ of the PCB pad's and components' dimensions. Notably, it can be calculated as $\mathrm{QR}_{\alpha}=\mathrm{N}_{\alpha} / \mathrm{N} \times 100 \%$, where $\mathrm{N}_{\alpha}$ is the number of components whose final (i.e., post-reflow) offsets are within $\alpha \%$ of the component's length and width dimension and $\mathrm{N}$ is the total number of components placed on a board. For example, by applying the industry standard from IPC to our PCB pads' and 
components' dimensions, a component with an offset smaller than $25 \%$ of the component size in both the length and width directions is treated as acceptable (i.e., pass). Therefore, the ratio of the acceptable components for each board is obtained from $\mathrm{QR}_{25}$.

In this research, we consider two kinds of $\alpha \in\{10,25\}$ to evaluate the performance of the placement not only for calculating the ratio of acceptable components (i.e., the number of passing components) but also for calculating the ratio of close-to-pad-center components (i.e., the number of optimally placed components). Also, we calculate the length $\left(\mathrm{L}_{-} \mathrm{QR}_{\alpha}\right)$ and width $\left(\mathrm{W}_{-} \mathrm{QR} \alpha\right)$ direction separately to investigate the difference in terms of the directional effects from self-alignment. The postreflow results of different types of components are listed in Table VII. The subgroup only includes the components that both the solder paste printing offsets and the component placement offsets are within $10 \%$ of the component dimensions.

Further, we compare the solder paste volume percentage between the acceptable and unacceptable components, i.e., the group whose offsets are within $\alpha \%$ of the component's size and the group whose offsets are beyond $\alpha \%$ of the component's size, which are represented as $\mathrm{N}_{\alpha}$ and $\left(\mathrm{N}-\mathrm{N}_{\alpha}\right)$ separately. The results regarding $\mathrm{QR}_{25}$ and $\mathrm{QR}_{10}$ are listed in Table VIII and Table IX, respectively.

Table VII shows that the smaller passive components' misalignment is more severe than that of large ones under identical solder paste printing and component placement conditions. And all the unacceptable components are caused by the unacceptable misalignment along the component width direction.

\section{Experimental results of moving distances along the length versus width directions}

The moving distances along the length and width directions can be compared through an examination of the ending positions of the different components on each board. The results are displayed in Figure 11 (a)-(f). In the figures, each dot stands for the mean value of 750 data points from one board for each kind of component. The red line represents the distance between the pad center and the solder paste center, and it is labeled as SPI. The blue line represents the distance between the pad center and the component center before the solder reflow process, where noted by PRE. The green line represents the distance from the pad center to the component center after the solder reflow, and it is labeled as POST. Each line is composed of 81 data points that correspond to the $81 \mathrm{DOE}$ boards. Therefore, the gaps between the blue line and the green line reflect the average moving distances of the components on each board during reflow.

Figure 10 shows that the average moving distances in component length direction are more extensive than that in width direction during reflow for all component types. The largest average moving distances of the 750 components on any of the 81 boards are (first value is length, second is width) $74.19 \mu \mathrm{m}$,

Table VII: The post-reflow results in terms of $\mathrm{QR}_{\alpha}(\%)$ for each component type

\begin{tabular}{|c|c|c|c|c|c|c|c|c|c|c|c|c|}
\hline \multirow{2}{*}{$\begin{array}{c}\text { Component } \\
\text { type }\end{array}$} & \multicolumn{6}{|c|}{ Data of all DOE boards } & \multicolumn{6}{|c|}{ Data of subgroup } \\
\hline & $\mathrm{QR}_{25}$ & $\mathrm{QR}_{10}$ & $\mathrm{~L}_{-} \mathrm{QR}_{25}$ & $\mathrm{~W}_{-} \mathrm{QR}_{25}$ & $\mathrm{~L}_{-} \mathrm{QR}_{10}$ & $\mathrm{~W}_{-} \mathrm{QR}_{10}$ & $\mathrm{QR}_{25}$ & $\mathrm{QR}_{10}$ & $\mathrm{~L}_{-} \mathrm{QR}_{25}$ & $\mathrm{~W}_{-} \mathrm{QR}_{25}$ & $\mathrm{~L}_{-} \mathrm{QR}_{10}$ & $\mathrm{~W}_{-} \mathrm{QR}_{10}$ \\
\hline R0402M & 90.82 & 47.84 & 100.00 & 90.82 & 94.53 & 50.77 & 98.94 & 66.68 & 100.00 & 98.94 & 94.70 & 70.30 \\
\hline R0603M & 95.77 & 58.23 & 100.00 & 95.77 & 97.3 & 59.87 & 99.44 & 75.32 & 100.00 & 99.44 & 98.38 & 76.67 \\
\hline R1005M & 99.77 & 82.89 & 100.00 & 99.77 & 99.30 & 83.47 & 99.96 & 93.96 & 100.00 & 99.96 & 99.64 & 94.31 \\
\hline
\end{tabular}

Table VIII: The solder paste volume percentage comparison between acceptable and unacceptable components regarding $\mathrm{QR}_{25}$

\begin{tabular}{|c|c|c|c|c|c|c|c|c|c|c|}
\hline \multirow{2}{*}{$\begin{array}{c}\text { Component } \\
\text { type }\end{array}$} & \multicolumn{4}{|c|}{ Data of $\mathrm{N}_{25}$} & \multicolumn{5}{c|}{ Data of $\left(\mathrm{N}-\mathrm{N}_{25}\right)$} \\
\cline { 2 - 12 } & Count & Mean & std & $\begin{array}{c}\text { 25th } \\
\text { percentile }\end{array}$ & $\begin{array}{c}75 \text { th } \\
\text { percentile }\end{array}$ & Count & Mean & std & $\begin{array}{c}\text { 25th } \\
\text { percentile }\end{array}$ & $\begin{array}{c}75 \text { th } \\
\text { percentile }\end{array}$ \\
\hline R0402M & 55173 & 79.67 & 7.72 & 74.02 & 84.84 & 5577 & 77.07 & 6.98 & 72.03 & 81.68 \\
\hline R0603M & 58182 & 78.00 & 9.20 & 71.66 & 83.95 & 2568 & 74.02 & 9.20 & 67.61 & 80.00 \\
\hline R1005M & 60610 & 83.20 & 9.31 & 76.80 & 89.32 & 140 & 79.74 & 11.08 & 72.00 & 87.24 \\
\hline
\end{tabular}

Table IX: The solder paste volume percentage comparison between acceptable and unacceptable components regarding $\mathrm{QR}_{10}$

\begin{tabular}{|c|c|c|c|c|c|c|c|c|c|c|}
\hline \multirow{2}{*}{$\begin{array}{c}\text { Component } \\
\text { type }\end{array}$} & \multicolumn{4}{|c|}{ Data of $\mathrm{N}_{10}$} & \multicolumn{5}{c|}{ Data of $\left(\mathrm{N}-\mathrm{N}_{10}\right)$} \\
\cline { 2 - 13 } & Count & Mean & std & $\begin{array}{c}\text { 25th } \\
\text { percentile }\end{array}$ & $\begin{array}{c}\text { 75th } \\
\text { percentile }\end{array}$ & Count & Mean & std & $\begin{array}{c}\text { 25th } \\
\text { percentile }\end{array}$ & $\begin{array}{c}\text { 75th } \\
\text { percentile }\end{array}$ \\
\hline R0402M & 29064 & 80.51 & 7.75 & 75.00 & 85.66 & 31686 & 78.45 & 7.51 & 72.92 & 83.47 \\
\hline R0603M & 35377 & 78.73 & 9.01 & 72.68 & 84.52 & 25373 & 76.55 & 9.40 & 69.82 & 82.85 \\
\hline R1005M & 50359 & 83.81 & 9.31 & 77.54 & 89.94 & 10391 & 80.12 & 8.72 & 73.85 & 86.12 \\
\hline
\end{tabular}


$25.75 \mu \mathrm{m}$ for R0402M; $120.48 \mu \mathrm{m}, 32.96 \mu \mathrm{m}$ for R0603M; and $204.52 \mu \mathrm{m}, 87.91 \mu \mathrm{m}$ for R1005M.

The components' offsets before and after the reflow process are calculated for the length and width direction individually. The components are grouped according to the placement settings, i.e., each group has a unique placement setting in the computer-aided design (CAD) file. Based on the results, for the length of R0402M, when the group average pre-reflow offset reaches $20 \%$ of the component size, the mean of post-reflow misalignment can be decreased to $2.5 \%$. For the width direction of $\mathrm{R} 0402 \mathrm{M}$, the largest group average pre-reflow offset is $24.15 \%$ of the components' size, the corresponding post-reflow misalignment can be decreased to $18.94 \%$. For R0603M, the means of post-reflow misalignment in the length direction can be reduced to $3.3 \%$ of the components' length even the group average pre-reflow offsets is up to $20.83 \%$. And for R1005M, the group average pre-reflow offset is $20.80 \%$ of the component's length, the means of post-reflow misalignment can be reduced to $2 \%$. Contrastingly, in the width direction, the largest group average pre-reflow offsets of R0603M and R1005M are $24.64 \%$ and $22.16 \%$, the corresponding group's means of post-reflow offset are diminished to $14.91 \%$ and $6 \%$, respectively. The selfalignment results in the width direction of $\mathrm{R} 1005 \mathrm{M}$ are better than those in smaller components. One possible cause for this variation is that R1005M has a larger pad size and higher solder paste volume, which may increase the restoring force and get large moving distances in the length and width directions. (a)

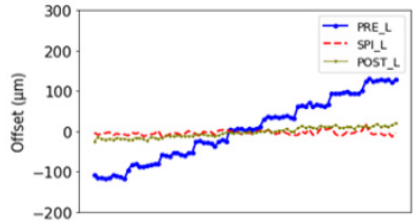

(c)

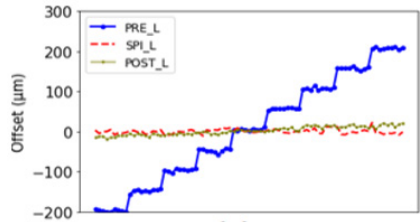

(e)

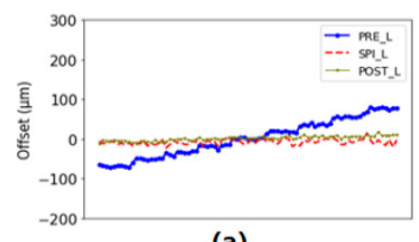

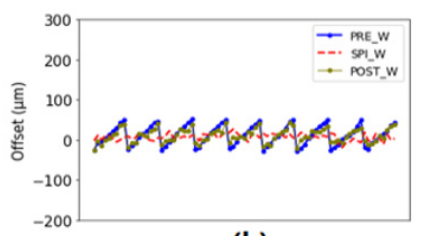

(b)

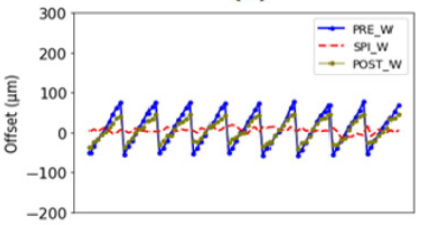

(d)

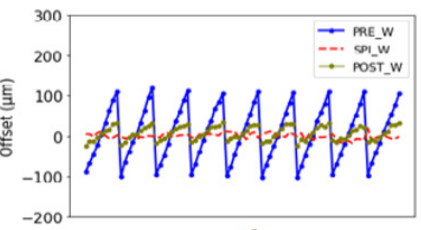

(f)
Figure 11: The offset values mean of each board along length and width direction for each component type Notes: (a) The offset values mean on R0402M length direction; (b) the offset values mean on R0402M width direction; (c) the offset values mean on R0603M length direction; (d) the offset values mean on R0603M width direction; (e) the offset values mean on R1005M length direction; ( $f$ ) the offset values mean on R1005M width direction.
Consequently, for all three kinds of small-scale passive components used in the experiment, the moving distances from placement positions with initial offsets toward the pad center in component length direction are notably more extensive than those in width direction during the reflow stage. Interestingly, they are opposite to the previously reported results of the experiments conducted on large-sized passive components.

\section{CONCLUSIONS}

The self-alignment characteristics in the length and width directions of smaller passive components are empirically investigated in this study. The experimental results showed that the yield decreased with the component's size decreased under the same solder paste printing and component placement conditions. The self-alignment was more effective in the length direction than the width direction, contrary to the previously reported studies $[5,15,16]$. All these observations suggest that the correct use of the self-alignment characteristics can enhance the assembly quality potentially.

Based on the 182,250 data of three sized passive components in our experiment, the percentage of unacceptable components is the greatest for the smallest components, e.g., R0402M, under the identical solder paste printing and component placement conditions. All the unacceptable components are failed because of misalignment in the width direction.

One potential reason for the different observations between this study and precursory research is that less solder paste applied on tiny components causes the restoring force to decrease correspondingly. The reduced restoring force has a more significant effect on the movement in the width direction than in the length direction. Consequently, self-alignment causes the components to move shorter distances in the width direction than in the length direction. However, the exact root causes have not been identified. For smaller passive components, accurate placement is highly recommended to achieve promising performances.

\section{ACKNOWLEDGMENT}

This work was partially supported by the collaborative research award with Koh Young Technology Inc. (grant \# 1152677) and the Integrated Electronics Engineering Center (IEEC) Pooled Research Award.

\section{REFERENCES}

[1] I. Parviziomran, S. Cao, H. Yang, S. Park, and D. Won, "Optimization of Passive Chip Components Placement with SelfAlignment Effect for Advanced Surface Mounting Technology," Procedia Manuf., vol. 39, pp. 202-209, 2019.

[2] R. Prasad, "Chapter1 Introduction to Surface Mount Technology," in Surface Mount Technology: Principles and Practice. Springer Science \& Business Media, 2013, ch.1, sec.1.3, pp 22-24.

[3] R. Strauss, "5 Reflowsoldering," in Surface Mount Technology. Butterworth-Heinemann, 1994, ch.5, sec.5.1, pp 144150. 
[4] O. Krammer and Z. Illyefalvi-Vitéz, "Investigating the self-alignment of chip components during reflow soldering," Per. Pol. Elec. Eng., vol. 52, no. 1-2, p. 67, Jan. 2008.

[5] M. Kong, S. Jeon, H. Au, C. Hwang, and Y.-C. Lee, "Development and Experimental Validation of a 3-D Solder Self-Alignment Model for Alignment Accuracy Prediction of Flip-Chip Assembly," IEEE Trans. Compon. Packag. Technol., vol. 1, no. 10, pp. 1523-1532, Oct. 2011.

[6] T. Hayashi, "An innovative bonding technique for optical chips using solder bumps that eliminate chip positioning adjustments," IEEE Trans. Compon., Hybrids, Manufact. Technol., vol. 15, no. 2, pp. 225-230, Apr. 1992.

[7] S. K. Patra and Y. C. Lee, "Quasi-Static Modeling of the Self-Alignment Mechanism in Flip-Chip Soldering-Part I: Single Solder Joint," J. Electron. Packag, vol. 113, no. 4, pp. 337-342, Dec. 1991.

[8] J. R. Ellis and G. Y. Masada, "Dynamic behavior of SMT chip capacitors during solder reflow," IEEE Trans. Compon., Hybrids, Manufact. Technol., vol. 13, no. 3, pp. 545-552, Sep. 1990.

[9] R. J. Klein Wassink and M. M. F. Verguld, "Drawbridging of Leadless Components,” Microelectron. Int., vol. 3, no. 1, pp. 18-24, Jan. 1986.

[10] O. Krammer, "Modelling the self-alignment of passive chip components during reflow soldering," Microelectron. Reliab., vol. 54, no. 2, pp. 457-463, Feb. 2014.

[11] "The Self-Alignment of Reflowed Surface Mount Components," Marki Microwave RF \& Microwave. https:// www.markimicrowave.com/blog/the-self-alignment-of-reflowedsurface-mount-components/ (accessed Sep. 30, 2020).

[12] J. Li, S. Poranki, R. Gallardo, M. Abtew, and R. Kinyanjui, "Design and Process Development for the Assembly of 01005 Passive Components," in SMTA International Conference Proceedings, San Diego, CA, USA, 2009, pp. 1-8.

[13] A. M. Najib, M. Z. Abdullah, A. A. Saad, Z. Samsudin, and F. C. Ani, "Experimental Study of Self-Alignment during Reflow Soldering Process," JAMT, vol. 12, no. 1(2), pp. 355-366, Aug. 2018.

[14] Kuo-Ning Chiang and Chang-An Yuan, "An overview of solder bump shape prediction algorithms with validations," IEEE Transactions on Advanced Packaging, vol. 24, no. 2, pp. 158-162, May 2001, doi: 10.1109/6040.928749.

[15] Surface Evolver Manual, Version 2.70, Mathematics Department Susquehanna University, Selinsgrove, PA, 2013, pp. 291.

[16] K. Pan, J. H. Ha, H. Y. Wang, V. Veeraraghavan, and S. B. Park, "The effect of solder paste volume on surface mount assembly self-alignment," Procedia Manuf., vol. 38, pp. 13811393, Jan. 2019.

[17] S. Cao, I. Parviziomran, H. Yang, S. Park, and D. Won, "Prediction of Component Shifts in Pick and Place Process of Surface Mount Technology Using Support Vector Regression," Procedia Manufacturing, vol. 39, pp. 210-217, Jan. 2019.

[18] Acceptability for Electronic Assemblies, IPC-A-610C, 2000 .

\section{BIOGRAPHIES}

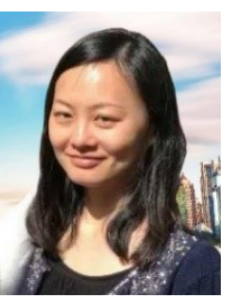

Jingxi He is currently a Ph.D. Candidate in the Department of Systems Science and Industrial Engineering, State University of New York at Binghamton. She holds a master's degree in System Science from the State University of New York at Binghamton, NY, and a bachelor's degree in Electrical Engineering from Hunan University, China. Her research interests include smart manufacturing, data analysis, and machine learning based advanced process control.

Yuqiao Cen received the B.S. degree in

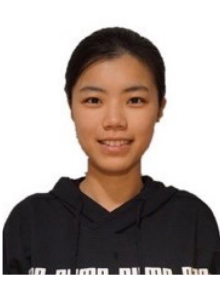
Engineering from Guangdong University of Technology, Guangdong, China, in 2015. Then she continued her education as a graduate student at New York University, in New York, USA, in 2016, emphasizing urban science and informatics. She is currently a Ph.D. candidate at the Department of Systems Science and Industrial Engineering of Binghamton University - SUNY, in New York, USA. Her research interests are machine learning, big data, and time series data analytics.

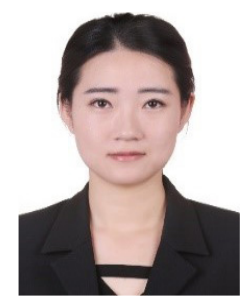

Yuanyuan Li received her BS degree in China Jiliang University, China, in 2017 and received her MS degree in Industrial and System Engineering at the State University of New York at Binghamton in 2019. Currently, she is a Ph.D. candidate in Industrial and Systems Engineering at the State University of New York at Binghamton. Her research interests include machine learning, modeling and simulation, and system optimization. She conducted some research on deep learningbased medical image classification and is one of the final lists of the "Best paper competition" of DAIS track of the Institute of Industrial and Systems Engineers (IISE) Conference. She is now working on the research that developing artificial intelligence solutions in the surface mount technology assembly line. She is also a member of Alpha Pi Mu and IISE.

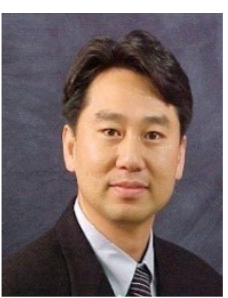

Prof. Seungbae (SB) Park is a Professor of Mechanical engineering of the State University of New York at Binghamton. He is also the director of Integrated Electronics Engineering Center (IEEC), a New York State Center for Advanced Technology (CAT). He received his B.S. and M.S. from Seoul National University and Ph.D. at Purdue University in 1994. Dr. Park began his professional career at IBM. He was responsible for the reliability of IBM's corporate flip chip technology in both leaded and lead-free solders and high performance packaging. Dr. SB Park started his academic career as a professor of mechanical engineering at the State University of New York at Binghamton in 2002. Professor Park is an expert in Modeling and Simulation for electronics components and systems integration. He has 
contributed in various $2.5 \mathrm{D} / 3 \mathrm{D}$ package development, MEMS packaging, reliability assessment of assemblies and systems, and smart electronics manufacturing. He has more than 200 technical publications and holds 4 US patents. Dr. Park served for several technical committees including a member of JEDEC 14-1 Reliability Committee, co-chair of iNEMI Modeling and Simulation TWG, chair of "Electronics Packaging" council in Society of Experimental Mechanics, and an associate editor for ASME Journal of Electronic Packaging. Professor Park has been helping consumer electronics and packaging companies such as Microsoft, Samsung, ASE, Xilinx, and Qualcomm, as a consultant.

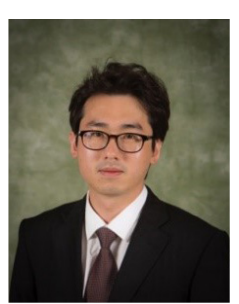

Dr. Daehan Won received a Ph.D. (2016) in industrial and systems engineering from the University of Washington, Seattle, WA. In 2016, he joined the Department of Systems Science and Industrial Engineering, Binghamton University, SUNY, and is currently an assistant professor. His research interests lie in mathematical programming in large-scale programming and data analytics/mining for various healthcare and manufacturing fields. He is recently working on designing new platforms for smart electronics manufacturing system to cope with advances in industry 4.0. He has published thirty-nine journal and conference papers, including Journal on Computing, IEEE CPMT, IEEE Intelligent Systems, etc. Dr. Won's research has been funded by industry partners such as Koh Young and Analog Devices and national consortium, such as Nano-Bio Manufacturing Consortium. He has been serving as multiple session chairs in international conferences, including the Institute Industrial and Systems Engineers (IISE) and the Institute for Operations Research and the Management Sciences (INFORMS). He received the best paper award in the Data Analysis and Information System track at the 2018 IISE conference. He named the finalist at the SAS data mining paper competition in INFORMS 2016. 